\title{
CASE STUDY: EXECUTION IN PUBLIC PLACES (BUS DEPOT)
}

\author{
Alfaz Mutwalli \\ Department of Mechanical Engineering \\ Sanjay Ghodawat University, Kolhapur \\ Maharashtra, India
}

\author{
Arif Mohammad Attar \\ Department of Mechanical Engineering \\ Sanjay Ghodawat Polytechnic, Kolhapur \\ Maharashtra, India
}

\begin{abstract}
The most important principal characteristics in routine existence are safety and cleanliness. The area involves insecure and harmful functions which causes human tragedies, delay in work, maximum number of unplanned and unexpected accidents caused due to unsafe condition and unsafe act. Unhealthy environment cause due to unclean area. The paper deals with execution of safety and cleanliness in bus depot. By this technique, it improves safety, cleanliness, healthy environment, efficiency and satisfactory production/repair of bus depot. The picture shown below indicates the unsafe and unclean act performed during existing and after execution. The paper also enhances a great morale boost for the workforce working in public places and promotes clean and efficient work flow.
\end{abstract}

Keywords - Data collection, clean area, Safe place, Improvement, Good appearance.

\section{INTRODUCTION}

Public places are important aspects of cities as they furnish improvements in habitual life. In spite these background of public places in progressing countries like India are far from beneficial in terms of quantity as well as standard (Trant J. et al. 21019). In various public places for example bus depot Safety and cleanliness, both are major factor relating for well regulated working area (Cooper M., 2000). Keeping the place safe and clean not only saves time and money but also safeguard the health and comfort of the visitors visiting public places. The physical and intellectual health of its workforce is a crucial part of maintaining good healthy environment (Francis J. et al. 2012). No one ever wants workplace to worry about safety hazards from an unclean environment and nobody wants to hear workforce complaining about a dirty bathroom or food/working area (khedkar A., 2008). Clean and safe environment promotes good mental and physical health (Hing C. et al. 2012).

Spitting at the wall, litter of garbage, smelling corners, unclean and unsafe condition for the worker to work in workshop, are some of the important aspects. Toilets with no doors, no buckets, no flush and use of toilets were paid to use.
No maintenance activity and no safety precaution were followed. Absence of dustbins and safety measures display. This technique helps to improve standard control or proper working condition of the workplace (Chauhan G., 2010). The intention of this paper is to execution safety and cleanliness and measure the existing and after execution performance of the bus depot.

Safety is the precaution to be taken to being protected to avoid the injuries to the man or machine. We need to establish common understanding about safety and health by emphasizing the importance of reporting different types of incidents to avoid accidents (Chauhan G. 2010) and prevent an unexpected and undesirable event, especially one resulting in fatality, or injury/ illness/ other loss (Carmana M. 2008). If preventable accidents are not stop due to our irresponsibility it is nothing but short of murder. If the safety methods are not followed an unplanned and unexpected accident may cause which may result into an injury or damage to health or property (Chakraborty K. 2011, Altman I. et al. 1989).

Cleanliness is the act which keeps the entire thing in very neat, clean and proper condition. Cleanliness is one of the most important aspects of nature and human life (Elnour G. et al 2013).Failing to ensure the cleanliness not only have harmful impact on our health and wellbeing of all of those around us but also has direct impact on our performance and workplace (Upadhye S., 2010). If any working place or material becomes dirty, we must spend extra work hours cleaning them and getting them back clean (Kumar K., 2012).

\section{METHODOLOGY}

At the beginning, visit the bus depot frequently and note all the observation. Focus what's right in front of you and around you. Visit every week and analyze whether there is any changes or not. Hereby, collect the most specific information and receive the relevant information. Never dismiss any information when feels useless. Separate the bus depot safety related observation and bus depot cleanliness related operation. Present the data in specific form such that it can be understood by everyone. After that, estimate the issue 


\section{International Journal of Engineering Applied Sciences and Technology, 2020 \\ Vol. 5, Issue 2, ISSN No. 2455-2143, Pages 408-412 \\ Published Online June 2020 in IJEAST (http://www.ijeast.com)}

observed with the result and then final conclude with higher authorities.

We observed a lot of safety related issues in the bus depot. We found that the electric wires attach to the battery were lying on the floor and electrical appliances were open which may cause electric shock and may lead to fire. Second thing we observed that the fire extinguisher was been expired, since many years it has not been refilled or replaced with the new one. The fire extinguisher was been damaged, rusted, depressurized and had loosed its ability to operate properly. Another thing we observed that the worker working in depot was been injured due to cutting tool which was lying on the floor and also safety shoes, goggles, apron, safety gloves were missing during working hours which may cause major damage to health and floor was slippery.

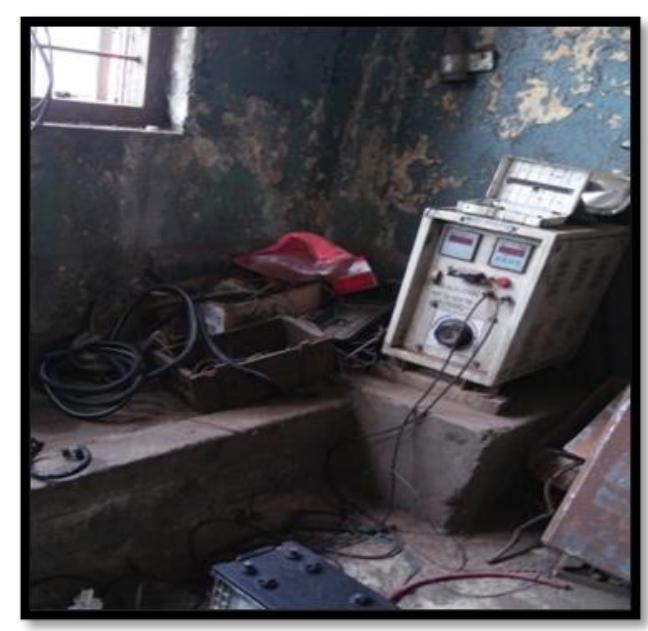

Fig. 1. Open electrical appliances

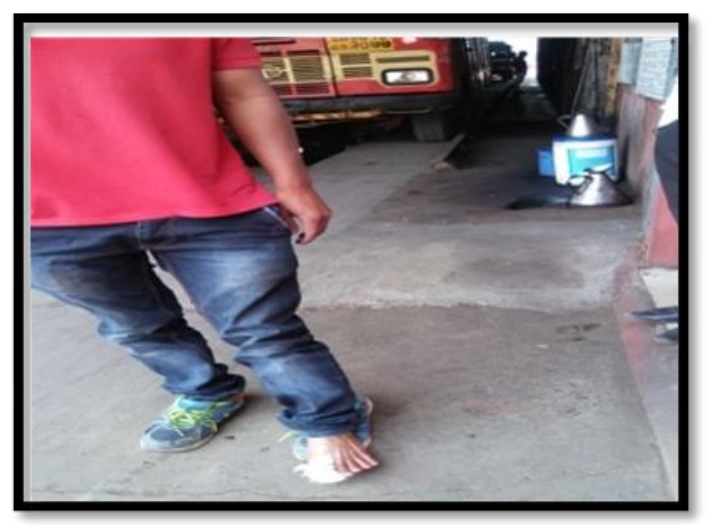

Fig. 2. Injury to worker

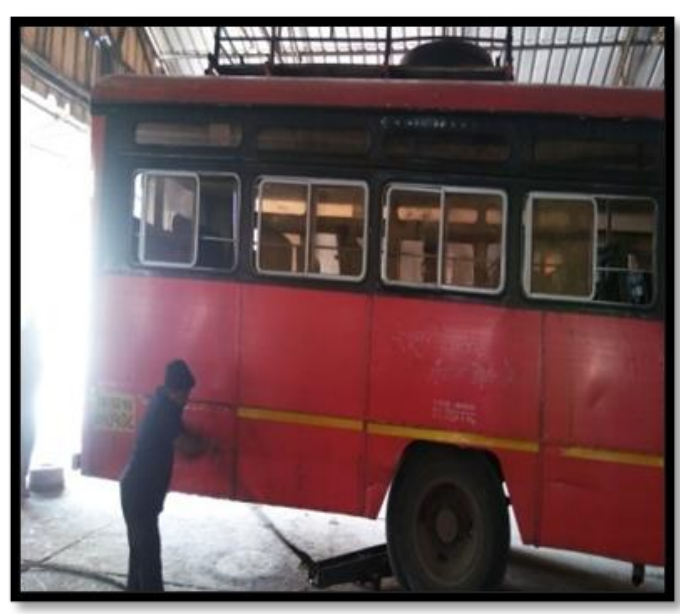

Fig. 3. Missing gloves

We observed a lot of cleanliness related issues in the bus depot. We found that uncertain condition of tiers and inner tubes which occupied more working space and created bad appearance for the new visitor. Second thing we observed that spare parts, metal tools and equipment were laying on the floor. Another thing we observed that dust-dirt and unclean washrooms may cause severe diseases like asthma problem, sneezing spread of harmful bacteria, and germs etc. leakage of oil on the floor and litter of garbage may lead to unclean/harmful environment.

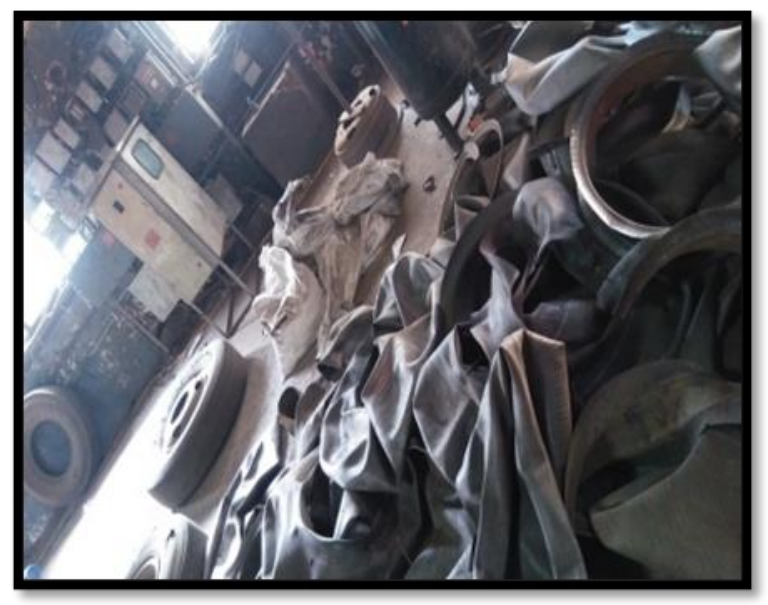

Fig. 4. Uncertain condition of tyre 


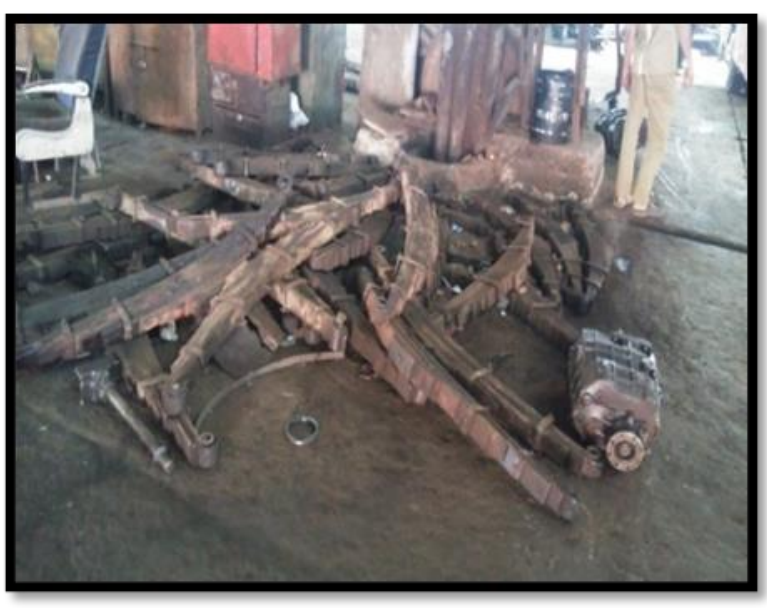

Fig. 5. Lying of spare parts

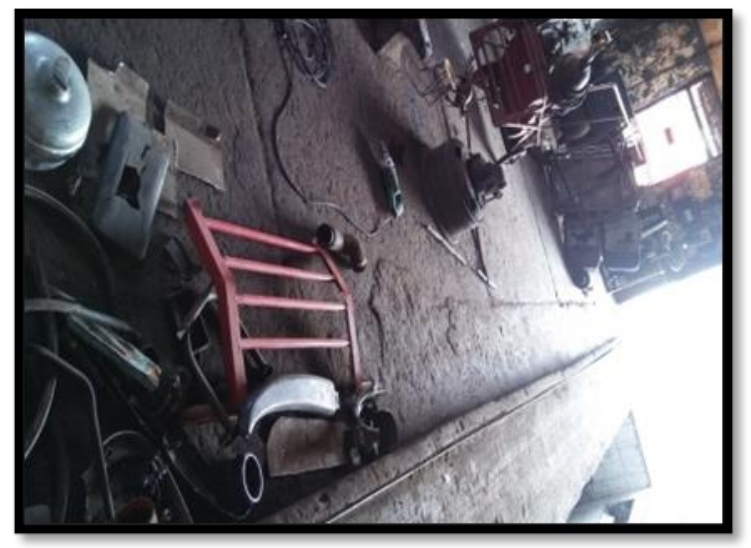

Fig. 6. Unclean floor

At the first settle upon a thesis, so as you can easily receive the relevant information from surrounding. Capture the happening around you which is the most important activity that can be carried out by observation. Once the information is captured, we call it data. Paying attention to each characteristic is very important. Once the information is captured note the observation. Next step is to present the data in most definite manner such that it is simply taken by others. The recorded data should be presented in chief details and only problem report should be presented. For example; fire extinguisher at first floor near head office is observed empty.

\section{RESULT}

Below pictures indicates the results achieved after execution in bus depot. Clean walking area, required item or parts are kept at designated places, cleanliness instruction boards are displayed, no unwanted items spread on floor, presence and use of dustbin, presence of cleanliness equipment, proper placement of tiers, proper placement of luggage, proper and safe electrical panel, clean public area and many more new results obtained.

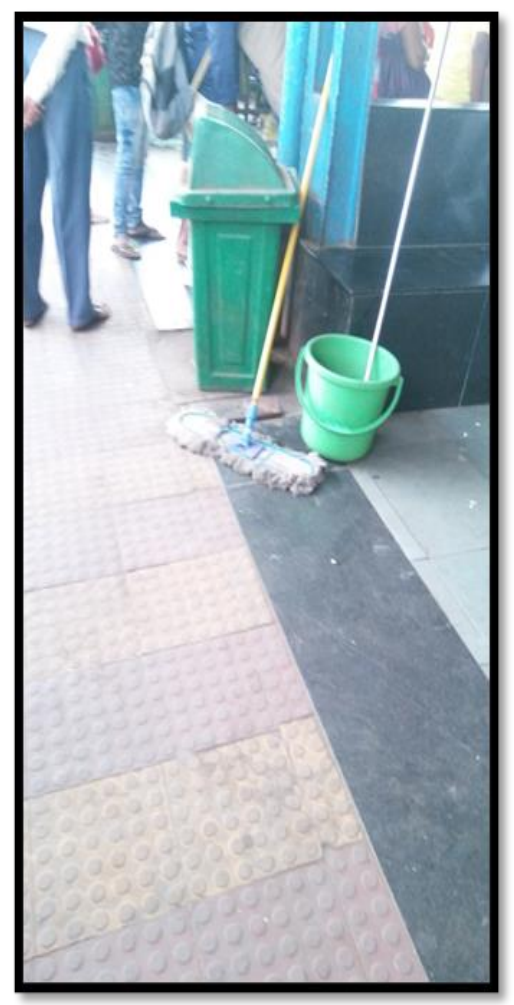

Fig. 7. Use of cleanliness equipment

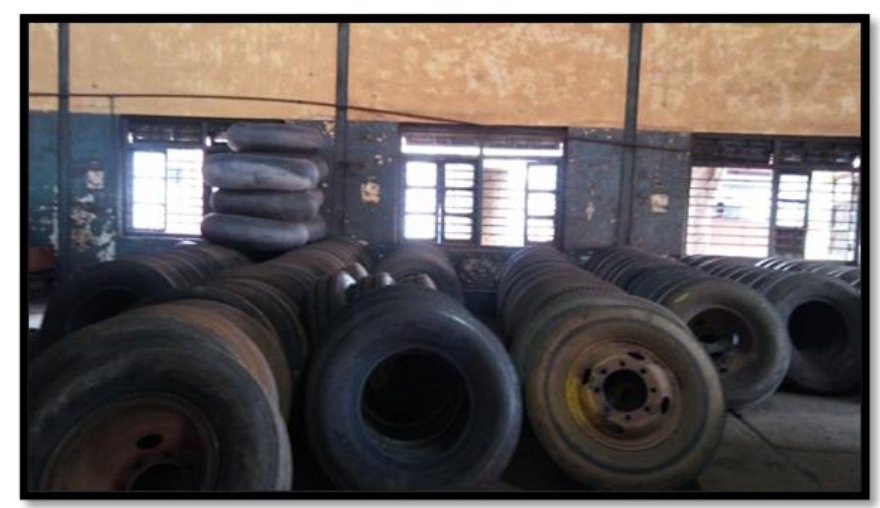

Fig. 8. Proper placement of tiers 
International Journal of Engineering Applied Sciences and Technology, 2020

Vol. 5, Issue 2, ISSN No. 2455-2143, Pages 408-412

Published Online June 2020 in IJEAST (http://www.ijeast.com)

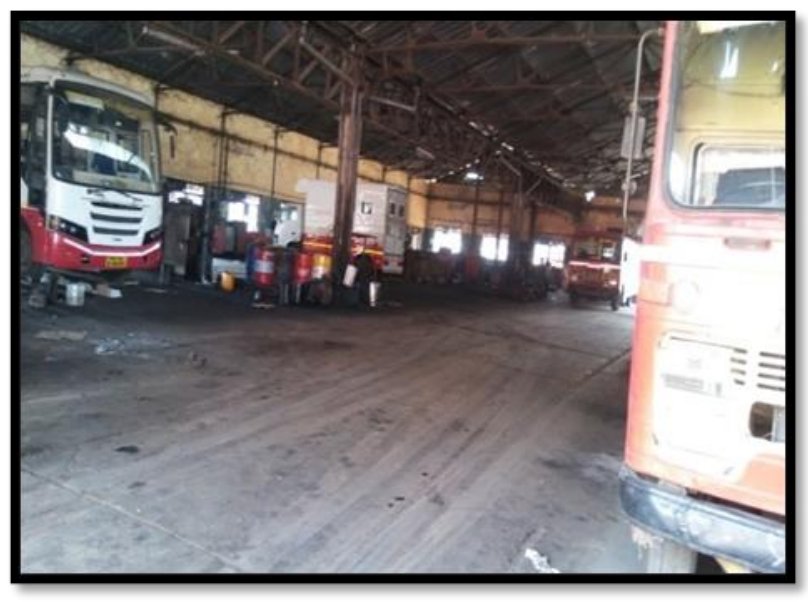

Fig. 9. Clean floor

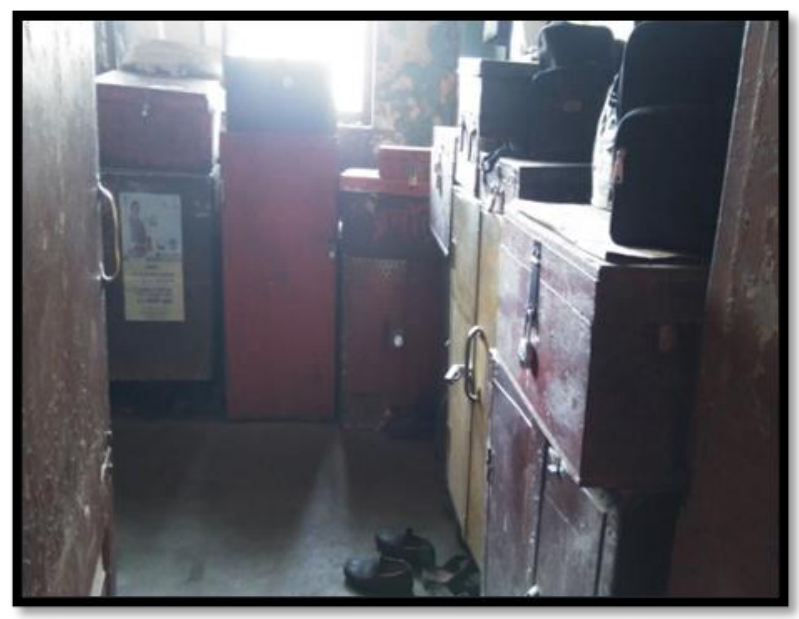

Fig. 10. Proper placement of luggage

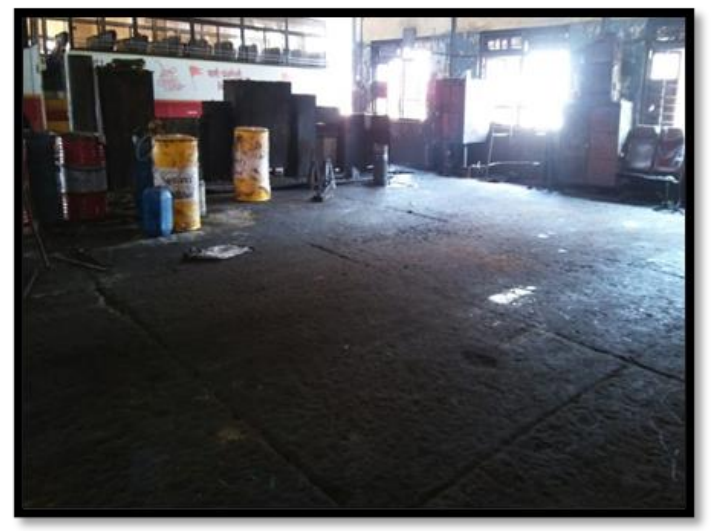

Fig. 11. Safe and proper electrical panel

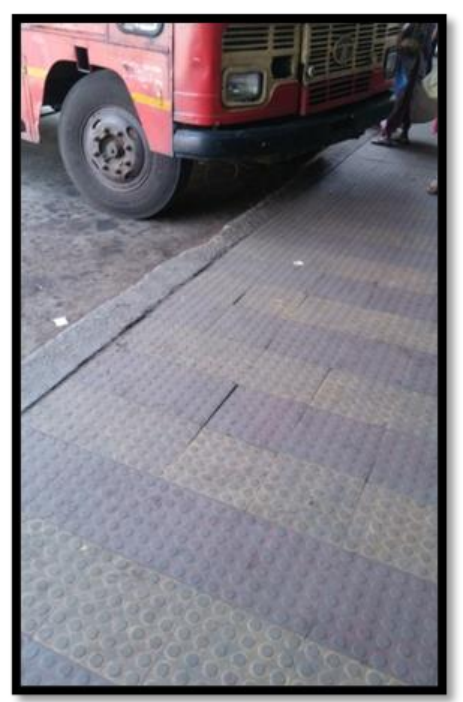

Fig. 12. Clean public area

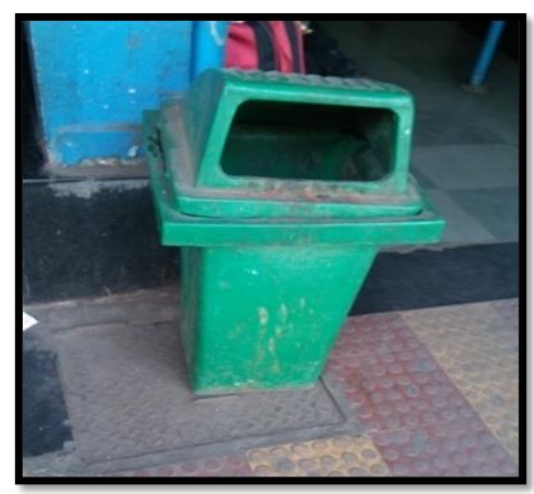

Fig. 13. Dustbin placed for garbage disposal

\section{CONCLUSION}

Let us now be aware and it's time to take step to minimize risk at public places. It's our duty and we need to be part of the safety and cleanliness measures. Risks are everywhere but how to handle the risk would make a big difference.

No spitting on the wall, no smelling of toilets, frequent cleaning of toilet, availability of plenty of water, proper disposal of garbage, clean floor, safety precaution, are been followed by the workforce, Chances of accidents due to lack of safety are reduced, etc. The existing picture shows how the area was unclean and no safety precaution was been followed but after execution the current picture shows the clean and safe public place. The visitors, workforce and higher authority were satisfied by the appearance of the clean and safe bus 
depot. As per the assessment, the pictures of new look of bus depot show the safer and cleaned working area.

\section{ACKNOWLEDGEMENT}

This project was supported by Professor Arifmohammad Attar. We thank workers who provided insight and expertise that greatly assisted the case study, although they may not agree with all of the interpretations/conclusions of this paper.

We thank Mr. Dayanand patil sir for immense guidance. We would also like to show our gratitude to Mr. Nigade sir for sharing their pearls of wisdom with us during the course of this research. We are also immensely grateful to the workers by sharing their opinion and suggesting their opinion for earlier version of the manuscript.

\section{REFERENCE}

1. Carmana M. (2008). Contemporary public spaces. Journal of urban design. (pp. 159-168).

2. Francis J., Giles B. and wood L. (2012). Creating sense of community. The role of public space. Journal of environmental psychology. (pp. 401-409).

3. Altman I. and Zube E. (1989). Public places and spaces. New York: plenum press. (pp. 159-1680).

4. Hing C. and Gunggutt H. (2012). Maintaining urban cleanliness: A new model. ASEAN conference on environment-behavior studies. (pp. 950-998).

5. Cooper M. (2000). Towards a model of safety culture. Journal of safety science, (pp.111-136).

6. Chauhan G. (2010). Measuring the status of lean manufacturing using AHP. International journal of Emerging technology vol.1 no.2, (pp.115-120).

7. Chakraborty K. (2011). Internal obstacles to quality for small scale industries. International Journal of Exclusive management research, vol. 1, (pp.1-9).

8. Upadhye S. (2010). Lean manufacturing system for medium size manufacturing enterprise. International journal of management science and engineering management. Vol.5, (pp.362-375).

9. Kumar k. (2012). Steps for implementation of $5 \mathrm{~s}$. International journal of management vol.2, (pp.402416).

10. Khedkar A. (2008). Study of implementing 5s techniques in plastic moulding. International journal of modern engineering research vol.2, (pp. 36533656).

11. Elnour G. and Laz H. (2013). Clean production in Auto repair workshop. Journal of applied and industrial sciences. (pp. 66-77).

12. Trant J. and Menard D. (2019). Review and critique of academic lab safety research. Nature chemistry. (pp. 1-9). 